\title{
Perancangan Web Jasa Penyewaan Sound System pada Eman Sounds
}

\author{
Ika Yuniva ${ }^{1}$, Andriansah ${ }^{2}$, M. Seprian Alfath Arkab ${ }^{3}$ \\ ${ }^{123}$ Program Studi Sistem Informasi, Universitas Bina Sarana Informatika, Indonesia \\ ${ }^{123} \mathrm{Jl}$. Kamal Raya No.18 Ring Road Barat, Cengkareng Jakarta Barat \\ ${ }^{* 1}$ Ika.iya@bsi.ac.id ; ${ }^{2}$ andriansah.aiy@bsi.ac.id; ${ }^{3}$ iya.aipt@gmail.com
}

\begin{abstract}
Eman Sounds is a business venture in the field of sound system rental services. The Eman sounds does not currently have a website application. The leasing service transaction system is still done conventionally, where if anyone wants to rent a sound system for a wedding or other official event can come directly to the Eman Sounds to see and rent it. For transaction reports sound system rental services are still recorded with paper so as to allow for data loss and errors in recording transactions. The purpose of this study is that the author will design a web sound system rental service for Eman Sounds so that it is expected to simplify the process of leasing transactions and making rental reports. The author uses the system development method, namely the waterfall model for this study. The use of PHP and HTML programming languages the author uses to create web rental services and MYSQL as the database. The results of this study are expected that with a web design sound system rental service can help Eman Sounds in the process of managing rental transactions and reports.
\end{abstract}

Keywords : Rental, Sound System, Web

\section{PENDAHULUAN}

Bisnis jasa penyewaan sound system sangat diperlukan bagi konsumen yang ingin menyewa sound system untuk kepentingan acara -acara resmi. Eman Sounds menyediakan beberapa paket jasa sewa sounds yang dapat dipilih oleh konsumen. Mekanisme penyewaan pada Eman Sounds masih dilakukan dengan cara konsumen dapat langsung datang untuk melihat dan menyewa sounds yang dinginkan. Sistem transaksi dan laporan jasa penyewaan masih menggunakan pencatatan kertas sehingga dikhawatirkan adanya kesalahan maupun kehilangan data dalam pencatatannya. Dalam hal ini maka penulis merancang sebuah web jasa penyewaan sound system.

Pada penelitian tentang rancangan web ini permasalahan yang dihadapi antara lain:

1. Dalam proses penyewaan masih konvensional, konsumen datang langsung ke Eman Sounds untuk melihat dan menyewa sound system yang diinginkan.

2. Media promosi jasa penyewaan masih konvensional, menggunakan spanduk.

3. Pencatatan transaksi jasa penyewaan dan laporan penyewaan masih manual menggunakan kertas.

Tujuan Penelitian ini dimaksudkan untuk:

1. Merancang sebuah web jasa penyewaan sound system untuk memudahkan dalam proses transaksi penyewaan sound systems

2. Memudahkan Eman Sounds dalam mempromosikan sound system menggunakan website.

3. Memudahkan Eman Sounds untuk mengelola data transaksi penyewaan dan pemuatan laporan. 
Berikut ini adalah landasan teori yang berkaitan dengan judul penelitian :

\section{a. Website}

"Website adalah sistem dengan informasi yang ditampilkan dalam bentuk teks, gambar, suara, dan lainnya yang tersimpan pada sebuah server web internet dalam bentuk hypertext"[1]

\section{b. Pengembangan Perangkat Lunak}

"Model Waterfall adalah model yang menyediakan pendekatan alur hidup perangkat lunak secara sekuensial atau terurut dimulai dari analisis, desain, pengodean, pengujian dan tahap pendukung".[2]

\section{c. ERD}

"ERD adalah suatu model jaringan yang menggunakan susunan data yang disimpan pada sistem secara abstrak". Perancang sistem menggunakan ERD untuk memodelkan data yang akan dikembangkan menjadi basis data (database)".[3]

\section{d. MYSQL}

"MySQL merupakan pengembangan database dari bahasa SQL ( Structure Query Languange). SQL adalah bahasa terstruktur yang dipakai sebagai interaksi antara script program dengan database server dalam hal pengolahan data"[4]

\section{e. Pengujian Web}

"Black box testing merupakan pengujian yang memungkinkan software engineer mendapatkan serangkaian kondisi input yang sepenuhnya menggunakan semua persyaratan fungsional untuk suatu program..[5]

\section{METODE PENELITIAN \\ Metode Pengumpulan Data}

Metode pengumpulan data yang digunakan penulis yaitu: Metode Observasi dan Studi Pustaka.

\section{Observasi}

Penulis melakukan pengamatan pada Eman Sounds untuk mengetahui proses jasa penyewaan sound system dan pada beberapa situs yang bersangkutan.

\section{Studi pustaka}

Penulis melakukan tinjauan pustaka dengan mengambil beberapa referensi yang berkaitan dengan judul penelitian.

\section{Metode Pengembangan Perangkat Lunak}

Penulis menggunakan model waterfall. Ada lima tahapan yang menjelaskan tentang metode waterfall [6]yaitu:

1. Analisis Kebutuhan Perangkat Lunak

Penulis melakukan pengamatan pada Eman Sounds untuk mengumpulkan data yang dibutuhkan pada perancangan web jasa penyewaan sound system.

2. Desain

Penulis menggunakan diagram ERD untuk penggambaran Model data

3. Pembuatan Kode Program

Penulis menuliskan coding program ke dalam bahasa pemograman PHP dan HTML.

4. Pengujian

Pada tahapan ini, penulis melakukan pengujian dengan blackbox testing terhadap rancangan web jasa penyewaan sound system untuk mengetahui apakah rancangan web yang telah dibuat sudah sesuai atau belum sehingga tidak terjadi kesalahan.

5. Pendukung (Support) dan Pemeliharaan (maintenance)

Pada tahapan ini rancangan web jasa penyewaan sound system dapat digunakan sehingga jika terjadi tingkat kesalahan atau error dapat diperbaiki, dan dapat juga dilakukan penambahan fitur atau fungsi web 
untuk pengembangan sistem.

\section{HASIL DAN PEMBAHASAN Analisa Kebutuhan Sistem}

Pada web jasa penyewaan sound system ini terdapat dua pengguna yang terdiri dari Admin, dan User. Kebutuhan dari masing-masing pengguna pada sistem ini sebagai berikut :

1. Halaman Admin

a. Admin dapat mengolah data paket sound system

b. Admin dapat mengolah data booking.

c. Admin dapat mengolah data konfirmasi pembayaran.

d. Admin dapat mencetak laporan pembayaran jasa penyewaan sound system.

2. Halaman User a. User harus melakukan registrasi terlebih dahulu untuk memesan sound system yang akan disewa

b. User dapat mengecek harga dan detail paket sound system dengan cara memilih menu paket.

c. User dapat melihat jadwal booking sound system yang akan disewa

d. User dapat melihat status pembayaran.

e. User dapat melakukan konfirmasi pembayaran.

f. User dapat mencetak bukti pembayaran.

\section{Desain}

\section{Rancangan Basis Data}

Pada rancangan web jasa penyewaan sound system ini nama databasenya yaitu db_emansound.sql yang terdiri dari beberapa tabel: login, konfirmasi,booking, paket dan rekening.

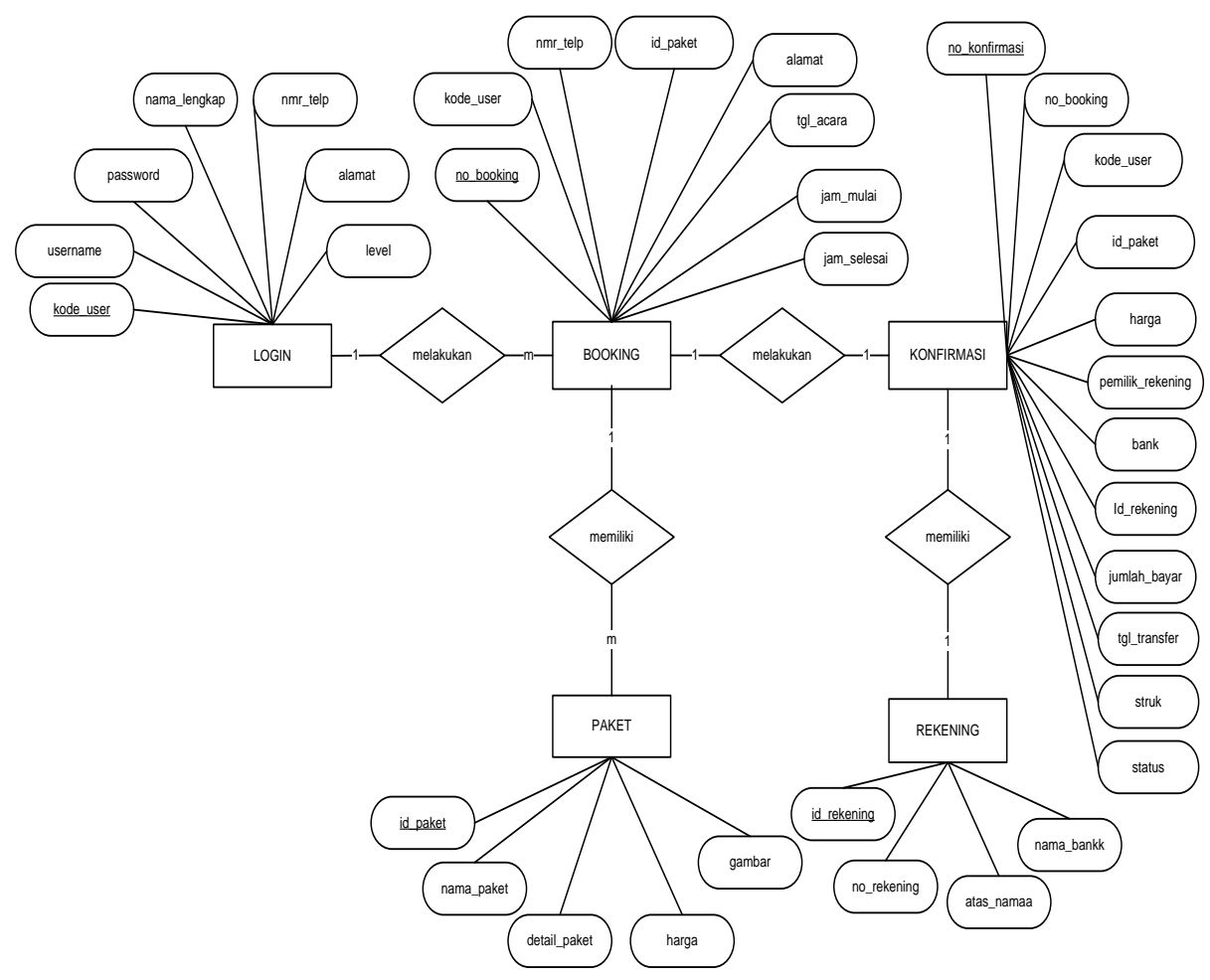

Gambar 1. Entity Relationship Diagram ( ERD ) Rancangan Web Jasa Penyewaan Sound System Pada Eman Sound 
Ika Yuniva, Andriansah, M. Seprian Alfath Arkab

Submitted: 2 Februari 2020; Revised: 19 Maret 2020; Accepted: 6 April 2020; Published: 27 April 2020

\section{Implementasi Rancangan Antarmuka}

a. Halaman Login

Pada halaman login user dapat melakukan login terlebih dahulu untuk dapat menggunakan menumenu pada halaman web jasa penyewaan sound system.

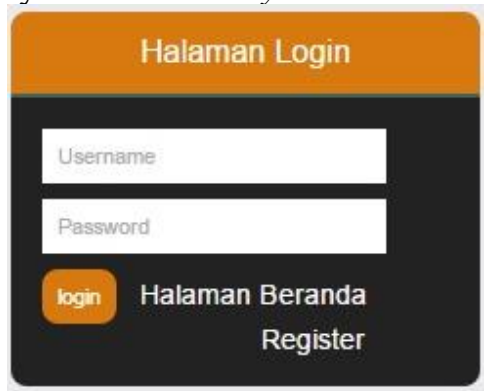

Gambar 2. Halaman Login b. Halaman Home

Pada halaman home user dapat mengakses halaman paket, jadwal, transaksi, bantuan dan lainnya. Gambar Halaman Home dapat dilihat pada Gambar 3.

c. Halaman Booking sewa sound system

Pada halaman ini user dapat mengisi data booking sewa paket sound system. Gambar halaman booking dapat dilihat pada Gambar 4

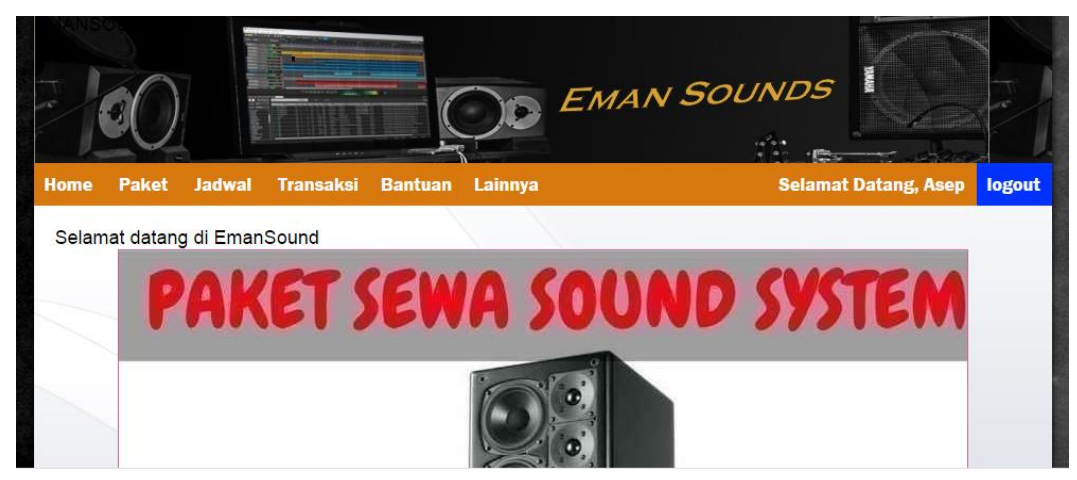

Gambar 3. Halaman Home

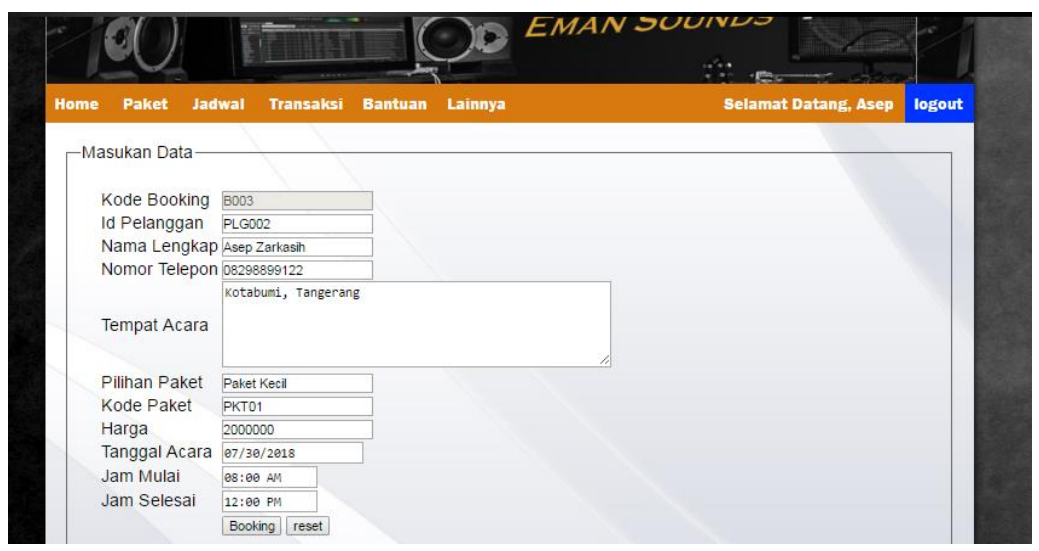

Gambar 4. Halaman Booking sewa sound system 


\section{Perancangan Web Jasa Penyewaan Sound System pada Eman Sounds}

d. Halaman Paket Sound system

Pada halaman ini user dapat memilih paket sound system yang akan disewa. Gambar halaman paket sound system dapat dilihat pada Gambar 5

e. Halaman Jadwal Sewa

Pada halaman ini user dapat melihat jadwal sewa sound system. Gambar

f. Halaman Laporan Pembayaran Sewa Sound System

Pada halaman ini admin dapat mengolah data laporan Pembayaran sewa sound system. Gambar halaman laporan pembayaran sewa sound system dapat dilihat pada Gambar 7 halaman jadwal sewa dapat dilihat pada Gambar 6

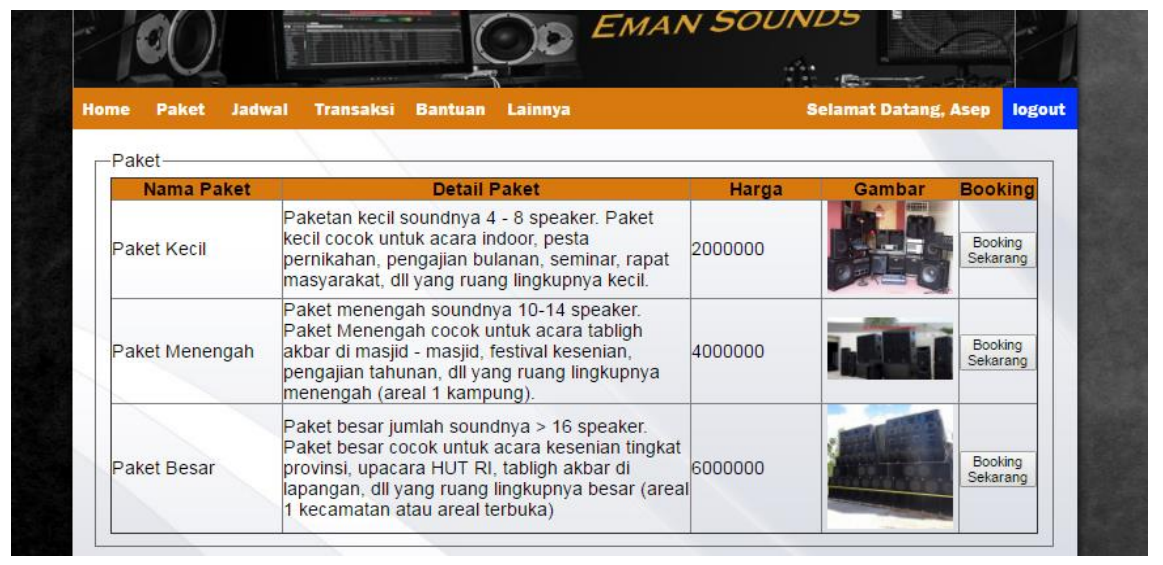

Gambar 5. Halaman Paket Sound System

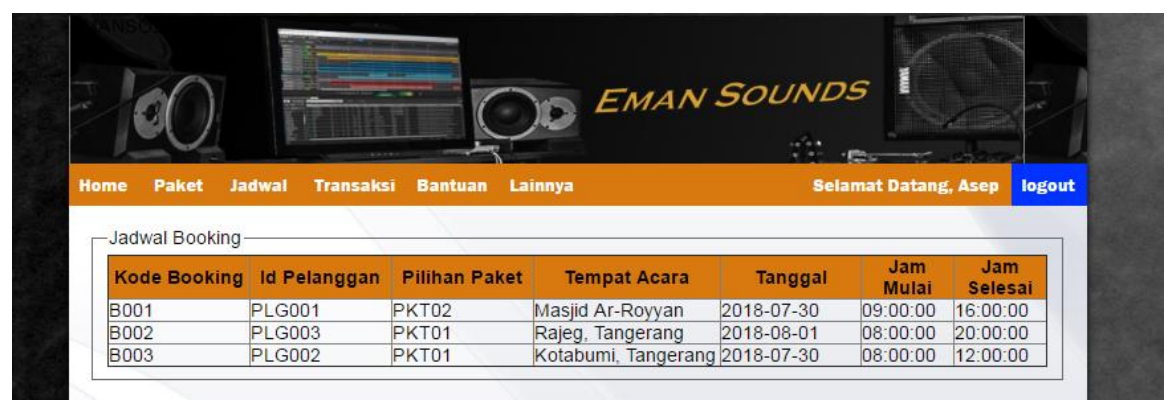

Gambar 6. Halaman Jadwal sewa

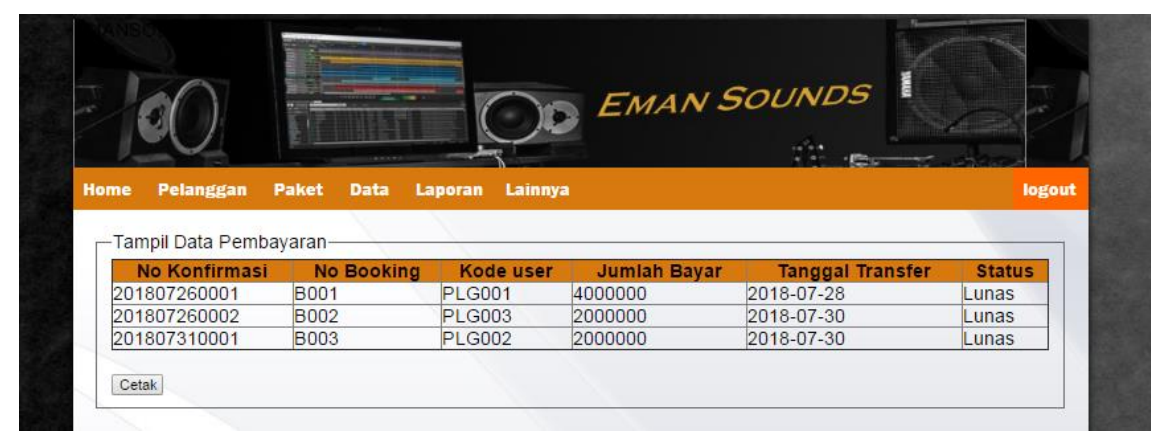

Gambar 7. Halaman Laporan Pembayaran Sewa Sound System

\section{Pembuatan Kode Program}


Salah satu kode program dalam rancangan web jasa penyewaan sound system pada Eman Sounds yaitu : Code untuk koneksi.php

$<$ ?php mysql_connect("localhost","root","')o $\mathrm{r}$

die("Access

server denied!".mysql_error()); mysql_select_db("db_emansound") or die("Access

Databases denied!".mysql_error()); ?>
Pengujian terhadap rancangan web jasa penyewaan sound system yang dibuat menggunakan black box testing sebagai proses masukan dan keluaran.

1. Pengujian Terhadap Halaman Login Black box testing pada pengujian halaman login dapat dilihat pada tabel 1

2. Pengujian Terhadap Halaman Booking Sewa Sound System

Black box testing pada pengujian halaman Booking Sewa Sound System dapat dilihat pada tabel 2

\section{Pengujian Unit}

Tabel 1.Black Box Testing Halaman Login

\begin{tabular}{|c|c|c|c|c|c|}
\hline No. & Skenario pengujian & Test case & $\begin{array}{l}\text { Hasil yang } \\
\text { diharapkan }\end{array}$ & $\begin{array}{c}\text { Hasil } \\
\text { pengujian }\end{array}$ & Kesimpulan \\
\hline 1. & $\begin{array}{l}\text { Username dan } \\
\text { password tidak diisi } \\
\text { kemudian klik } \\
\text { tombol login }\end{array}$ & $\begin{array}{l}\text { Username: } \\
\text { (kosong) } \\
\text { Password: } \\
\text { (kosong) }\end{array}$ & $\begin{array}{l}\text { Sistem akan } \\
\text { menolak dan } \\
\text { menampilkan } \\
\text { "Username/Passwo } \\
\text { rd tidak boleh } \\
\text { kosong" }\end{array}$ & $\begin{array}{l}\text { Sesuai } \\
\text { harapan }\end{array}$ & Valid \\
\hline 2. & $\begin{array}{l}\text { Mengetikkan } \\
\text { username dan } \\
\text { password tidak diisi } \\
\text { atau kosong } \\
\text { kemudian klik } \\
\text { tombol login } \\
\end{array}$ & $\begin{array}{l}\text { Username: } \\
\text { Asep } \\
\text { Password: } \\
\text { (kosong) }\end{array}$ & $\begin{array}{c}\text { Sistem akan } \\
\text { menolak akses dan } \\
\text { menampilkan } \\
\text { "Username/Passwo } \\
\text { rd tidak boleh } \\
\text { kosong" } \\
\end{array}$ & $\begin{array}{l}\text { Sesuai } \\
\text { harapan }\end{array}$ & Valid \\
\hline 3. & $\begin{array}{l}\text { Username tidak diisi } \\
\text { (kosong) dan } \\
\text { password diisi } \\
\text { kemudian klik } \\
\text { tombol login }\end{array}$ & $\begin{array}{l}\text { Username: } \\
\text { (kosong) } \\
\text { Password: } \\
\text { 1998-03-31 }\end{array}$ & $\begin{array}{c}\text { Sistem akan } \\
\text { menolak akses dan } \\
\text { menampilkan } \\
\text { "Username/Passwo } \\
\text { rd tidak boleh } \\
\text { kosong" }\end{array}$ & $\begin{array}{l}\text { Sesuai } \\
\text { harapan }\end{array}$ & Valid \\
\hline 4. & $\begin{array}{l}\text { Mengetikkan salah } \\
\text { satu kondisi salah } \\
\text { pada username atau } \\
\text { password kemudian } \\
\text { klik tombol login }\end{array}$ & $\begin{array}{l}\text { Username: } \\
\text { Asep } \\
\text { (benar) } \\
\text { Password: } \\
\text { 1998-03-31 } \\
\text { (salah) }\end{array}$ & $\begin{array}{c}\text { Sistem akan } \\
\text { menolak akses dan } \\
\text { menampilkan } \\
\text { "Login gagal, } \\
\text { username/password } \\
\text { salah, silahkan coba } \\
\text { lagi!" } \\
\end{array}$ & $\begin{array}{l}\text { Sesuai } \\
\text { harapan }\end{array}$ & Valid \\
\hline 5. & $\begin{array}{c}\text { Mengetikkan } \\
\text { username dan } \\
\text { password dengan } \\
\text { data yang benar } \\
\text { kemudian klik } \\
\text { tombol login }\end{array}$ & $\begin{array}{l}\text { Username: } \\
\text { Asep } \\
\text { (benar) } \\
\text { Password: } \\
\text { 1998-03-31 } \\
\text { (benar) }\end{array}$ & $\begin{array}{l}\text { Sistem menerima } \\
\text { akses login dan } \\
\text { kemudian langsung } \\
\text { menampilkan menu } \\
\text { utama. }\end{array}$ & $\begin{array}{c}\text { Sesuai } \\
\text { harapan }\end{array}$ & Valid \\
\hline
\end{tabular}


Perancangan Web Jasa Penyewaan Sound System pada Eman Sounds

Tabel 2.Black Box Testing Halaman Booking

\begin{tabular}{|c|c|c|c|c|c|}
\hline No. & Skenario pengujian & Test case & $\begin{array}{l}\text { Hasil yang } \\
\text { diharapkan }\end{array}$ & Hasil pengujian & Kesimpulan \\
\hline 1. & $\begin{array}{l}\text { Data booking tidak } \\
\text { diisi dengan lengkap, } \\
\text { kemudian klik } \\
\text { tombol booking. }\end{array}$ & $\begin{array}{l}\text { Nomor Telepon: } \\
\text { (kosong) } \\
\text { Tempat Acara: } \\
\text { (kosong) } \\
\text { Tanggal Acara: } \\
\text { (kosong) } \\
\text { Jam Mulai: } \\
\text { (kosong) } \\
\text { Jam Selesai: } \\
\text { (kosong) }\end{array}$ & $\begin{array}{l}\text { Sistem akan } \\
\text { menolak dan } \\
\text { menampilkan } \\
\text { "Data tidak boleh } \\
\text { kosong" }\end{array}$ & Sesuai harapan & Valid \\
\hline 2. & $\begin{array}{l}\text { Data booking diisi } \\
\text { dengan lengkap, } \\
\text { kemudian klik } \\
\text { tombol booking. }\end{array}$ & $\begin{array}{l}\text { Nomor Telepon: } \\
\text { 0839129332 } \\
\text { Tempat Acara: } \\
\text { Tangerang } \\
\text { Tanggal Acara: } \\
\text { 08/06/2018 } \\
\text { Jam Mulai: } \\
\text { 10:00:AM } \\
\text { Jam Selesai } \\
\text { :08.00PM }\end{array}$ & $\begin{array}{l}\text { Sistem akan } \\
\text { menerima dan } \\
\text { menampilkan } \\
\text { "Data berhasil di } \\
\text { tambah" }\end{array}$ & Sesuai harapan & Valid \\
\hline
\end{tabular}

\section{KESIMPULAN DAN SARAN}

Penulis mencoba menarik kesimpulan dari pembahasan sebelumnya yaitu :

1. Dengan adanya rancangan web jasa penyewaan sound system pada Eman Sounds ini diharapkan dapat memudahkan konsumen yang ingin menyewa sound system.

2. Mempermudah Eman Sounds sebagai pengelola untuk mempromosikan paket sewa sound system

3. Mempermudah Eman Sounds dalam mengelola laporan dan transaksi jasa penyewaan sound system

Penulis memberikan beberapa saran untuk penelitian selanjutnya agar rancangan web jasa penyewaan sound system bisa lebih baik dan optimal. Berikut saran-saran yang dapat penulis

berikan :

1. Diperlukan adanya backup data untuk rancangan web jasa penyewaan sound system pada Eman Sounds yang disimpan agar tidak terjadi kesalahan.

2. Pada rancangan web jasa penyewaan sound system pada Eman Sounds perlu adanya penambahan menu yang menarik lebih banyak pengunjung agar banyak yang menyewa sound system.

3. Diharapkan adanya upaya untuk pemeliharaan software juga hardware demi keberlangsungan web jasa penyewaan sound system pada Eman Sounds

\section{DAFTAR PUSTAKA}

[1] Murad. Dina Fitria, Kusniawati. Nia, Asyanto. Agus 2013, "Aplikasi Intelligence Website Untuk Penunjang Laporan PAUD Pada Himpaudi Kota Tangerang”, Jurnal CCIT. Tangerang: Perguruan Tinggi Raharja.Vol. 7, No. 1, September 2013.

[2] Sukamto, Rosa Ariani dan Muhammad Shalahuddin. 2013, "Rekayasa Perangkat Lunak Terstruktur dan Berorientasi Objek", Bandung: Informatika.

[3] Wahyuni, T., \& Hasan, N. 2017, "Perancangan Penjualan Produk Busana Muslim Syar'i Berbasis Web Pada Nadzwa Collection Purworejo", 6(1), 46-52.

[4] Sugiri dan Haris Saputro, 2008, "Pengelolaan Database MySQL Dengan PhpMyadmin", Graha Ilmu. Yogyakarta 
Ika Yuniva, Andriansah, M. Seprian Alfath Arkab

Submitted: 2 Februari 2020; Revised: 19 Maret 2020; Accepted: 6 April 2020; Published: 27 April 2020

[5] Sutabri, Tata. 2012, "Analisis Sistem Informasi", Yogyakarta: Andi Offset.

[6] Sagita, R. A., \& Sugiarto, H. 2016, "Penerapan Metode Waterfall Pada Sistem Informasi Penjualan Furniture Berbasis Web", Indonesian Journal on Networking and Security, 5(4), 49-55. 